\title{
Cyclosporin A Inhibits Albumin Synthesis in Huh7 Cells
}

\author{
Youn Joo Jeon ${ }^{1}$ and Yong Soo $\mathrm{Kim}^{2}$
}

${ }^{1}$ Bupyoung Internal Medicine Clinic, Incheon; ${ }^{2}$ Division of Nephrology, Department of Internal Medicine, The Catholic University of Korea School of Medicine, Seoul, Korea

Background/Aims: Hypoalbuminemia occurs frequently in renal transplant recipients immediately after renal transplantation. We studied the regulation of hepatic albumin synthesis by cyclosporin A (CsA) in Huh7 cells.

Methods: Huh7 cells were incubated with various concentrations of CsA for 4, 8, 16, and 24 hours. Albumin was measured in Huh7 cell-conditioned medium by sandwich enzyme-linked immunosorbent assay and Western blot. Albumin mRNA expression was analyzed by Northern blotting in CsA-treated cells.

Results: CsA $\left(10^{-7}-10^{-4} \mathrm{M}\right)$ inhibited albumin synthesis in Huh7 cells in a dose- dependent manner. A Western blot analysis for albumin in the conditioned medium released from CsA-treated $\left(10^{-7}-10^{-5} \mathrm{M}\right)$ cells also showed significant inhibition of albumin synthesis in a dose-dependent manner. Vehicle (olive oil) did not affect albumin synthesis. In contrast, a Northern blot analysis revealed no inhibition of albumin mRNA expression by CsA at any time point from 1-24 hours, indicating that the inhibition of albumin synthesis occurred at the translational level.

Conclusions: Our results suggest that inhibition of hepatic albumin synthesis by high dose CsA contributes to the hypoalbuminemia in renal transplant recipients.

Keywords: Cyclosporin A; Albumins; Kidney transplantation; Hypoalbuminemia

\section{INTRODUCTION}

Hypoalbuminemia occurs frequently during the early post-renal transplantation period in renal transplant recipients. Hypoalbuminemia, followed by low intravascular volume, delays the onset of urine output, decreases urine volume, delays recovery of renal function, and increases the rate of delayed graft function [1]. Patients undergoing various surgical procedures show transient hypoalbuminemia that occurs during the early post-operative period (usually within the first week) [2,3]. In contrast, we have experienced long-lasting, noticeable hypoalbuminemia, often associated with decreased urine output, slowly re- covering or even worsening renal function that was initially recovering, and ascites formation in renal transplant recipients during the early post-operative period.

In a retrospective analysis of 200 renal transplant recipients at our center, serum albumin levels decreased by more than $0.5 \mathrm{~g} / \mathrm{dL}$ in $44 \%$ of recipients during the first month after the operation. The lowest serum albumin levels were observed at post-operative day 14, which recovered to pre-operative levels at 60 days after the operation. We have also observed that an albumin infusion recovers urine output and renal function very quickly in cases of hypoalbuminemia-induced renal dysfunction.

Hypoalbuminemia generally results from decreased 
hepatic synthesis, increased catabolism, protein loss from the intravascular space, or plasma dilution. Protein loss could not explain the hypoalbuminemia in our transplant recipients, because most of our recipients were orally fed for 2 days, and losses in wound drainage were minimal. We found no correlation between changes in serum albumin levels and changes in body weight, indicating that plasma dilution was not the cause for the hypoalbuminemia.

High-dose cyclosporin A (CsA) is routinely administered to renal transplant recipients during the early postoperative period, and this drug is well known to be hepatotoxic and to regulate hepatic enzymes including cytochrome P45o. CsA inhibits hepatic protein synthesis, probably at the translation level, based on in vitro and in vivo experiments [4-6]. However, it has not been clearly determined if CsA regulates hepatic albumin synthesis.

In this study, we examined albumin gene expression in a CsA-treated human hepatoma cell line, Huh7 cells, and measured albumin in the conditioned medium released from CsA-treated cells and albumin gene expression in the same cells.

\section{METHODS}

\section{Cell culture}

Huh7 cells, a human hepatoma cell line, were maintained in Modified Eagle's medium (MEM) supplemented with $10 \%$ heat inactivated fetal bovine serum and an antibiotic/antifungal solution. Cell cultures were maintained at $37^{\circ} \mathrm{C}$ under $5 \% \mathrm{CO}_{2}$. All cell culture materials were purchased from Gibco BRL (Gaithersburg, MD, USA).

\section{Enzyme-linked immunosorbent assay}

Albumin in the conditioned medium released from Huh7 cells was measured by a sandwich enzyme-linked immunosorbent assay (ELISA). To observe the dose response of CsA (Sandoz, Seoul, Korea) to albumin synthesis, the cells were plated in six-well dishes, grown to confluence, and incubated in $1 \mathrm{~mL}$ of fresh serumfree MEM medium with or without various doses of CsA. After 24 hours, the conditioned medium was collected, centrifuged at $10,000 \times \mathrm{g}\left(4^{\circ} \mathrm{C}\right)$ for 3 minutes, and stored at $-70^{\circ} \mathrm{C}$ until assay. For the albumin ELISA, rabbit anti-human albumin antibody $(1: 4,000)$ (DAKO,
Glostrup, Denmark) was used as the capture antibody and horseradish peroxidase-conjugated rabbit anti-human albumin antibody $(1: 2,000)$ (DAKO) was used as the detection antibody. O-Phenylenediamine dihydrochloride (Gibco BRL) was used as the enzyme substrate, and human serum albumin (Green Cross Corp., Seoul, Korea) was used as the standard.

\section{Western blot analysis}

Confluent Huh7 cells, plated in six-well dishes, were incubated in $1 \mathrm{~mL}$ of fresh serum-free medium with or without various doses of CsA for 24 hours, and the medium was collected. The conditioned medium was centrifuged at $16,000 \times \mathrm{g}$ for 15 minutes at $4^{\circ} \mathrm{C}$, and protein concentration of the conditioned medium was determined using the Bradford protein bioassay (BioRad, Hercules, CA, USA). The conditioned medium was heated at $94^{\circ} \mathrm{C}$ for 5 minutes in sample buffer. Proteins were separated by SDS-PAGE on $7.5 \%$ polyacrylamide gels and were electroblotted onto a Bio-Blot nitrocellulose membrane (Costar, Cambridge, MA, USA). Nonspecific binding was blocked by incubating the blots for 1 hour in $5 \%(\mathrm{w} / \mathrm{v})$ nonfat milk. Albumin was detected by an overnight incubation with a rabbit anti-human albumin antibody $(1: 1,000)$. The primary antibody incubation was followed by six washes in Tris-buffered saline with $0.005 \%$ Tween20. The blot was then incubated with horseradish peroxidase-conjugated anti-rabbit IgG (Amersham Life Science, Little Chalfont, UK) at 1:2,000 for 30 minutes. Antibody reactive protein was detected using enhanced chemiluminescence (Amersham Life Science).

\section{RNA Isolation and Northern blot analysis}

Confluent Huh7 cells, plated in $10 \mathrm{~cm}$ dishes, were inc ubated in $4 \mathrm{~mL}$ of fresh serum-free medium with or without various doses of CsA for 24 hours to test the effect of CsA on albumin gene expression. For the time course, cells were incubated with or without $\mathrm{CsA}\left(10^{-6} \mathrm{M}\right)$ for the indicated time points. RNA was isolated by one-step guanidium-thiocyanate-phenol-chloroform extraction. RNA concentration was measured by absorbance at 260 $\mathrm{nm}$. RNA quantification and integrity were confirmed by $1 \%$ agarose gel electrophoresis and ethidium bromide staining. Total RNA was fractionated by electrophoresis on a $1 \%$ agarose-formaldehyde gel and blotted by capillary transfer onto a nylon membrane (Gene Screen, NEN, 
Boston, MA, USA) and cross-linked with UV irradiation (UV Strata-linker180o, Stratagene, Cedar Creek, TX, USA). The membrane was probed with human albumin cDNA (ATCC\# 59713, $1.0 \mathrm{~kb}$ ) labeled by random priming using a commercial kit (Amersham Life Science) and $\left[32^{\mathrm{P}}\right]$ dCTP. The blot was prehybridized at $42^{\circ} \mathrm{C}$ for 2 hours in $50 \%$ formamide, $0.1 \%$ SDS, $2 \times$ Denhardt's solution, $5 \times$ SSPE, and $0.1 \mathrm{mg} / \mathrm{mL}$ salmon sperm DNA. Probe $\left(10^{6}\right.$ $\mathrm{cpm} / \mathrm{mL}$ ) was added to the prehybridization solution, and the blot was hybridized for 16 hours at $42^{\circ} \mathrm{C}$. The blot was then washed twice for 15 minutes at $55^{\circ} \mathrm{C}$ in $2 \times$ standard saline citrate and $0.1 \%$ SDS, and autoradiography was performed with Fuji X-ray film and an intensifying screen at $-70^{\circ} \mathrm{C}$. The albumin probe was then removed by boiling, and the same blot was rehybridized to a cDNA probe encoding the 36B4 ribosomal protein. Densitometric analysis was used to detect the intensity of the albumin and $36 \mathrm{~B} 4$ signals.

\section{Statistical analysis}

Statistical comparisons between multiple groups were performed with an analysis of variance, and Bonferroni's method was applied to control for multiple testing. A $p$ value $<0.05$ was considered statistically significant.

\section{RESULTS}

\section{Albumin synthesis in Huh7 cells}

Confluent Huh7 cells incubated for 24 hours secreted large amounts of albumin $(5.18 \pm 0.49 \mu \mathrm{g} / \mathrm{mL})$. CsA significantly decreased the albumin release in a dosedependent manner $(p<0.01)$. Vehicle (olive oil) did not affect the albumin concentration in conditioned medium. CsA inhibited albumin synthesis by $48 \%, 60 \%$ and $82 \%$ at concentrations of $10^{-6} \mathrm{M}, 10^{-5} \mathrm{M}$, and $10^{-4} \mathrm{M}$, respectively (Fig. 1A). The inhibition of albumin synthesis by CsA was statistically significant at 24 hours (Fig. 1B). A Western blot analysis for albumin in the conditioned medium released from Huh7 cells also revealed that CsA inhibited albumin synthesis in a dose-dependent manner at doses from $10^{-7} \mathrm{M}$ to $10^{-5} \mathrm{M}$, whereas the vehicle did not (Fig. $1 \mathrm{C}$ ).

\section{Cell viability}

Cell viability was tested by staining the cells from each
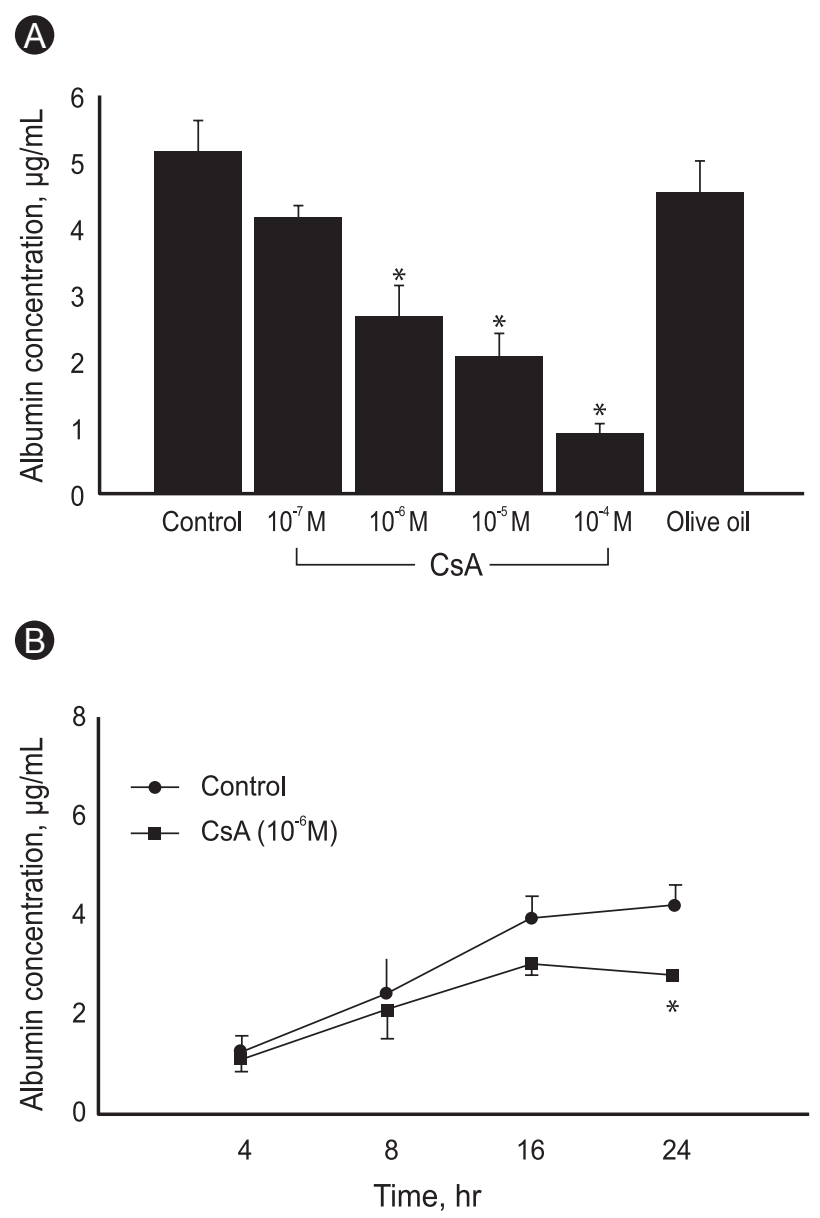

C

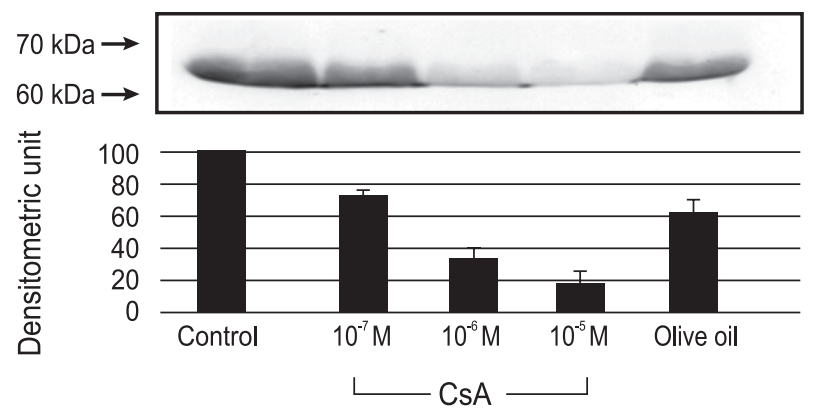

Figure 1. Albumin concentration in the conditioned medium was measured in untreated- and cyclosporine A (CsA)-treated Huh7 cells. (A) Confluent cells were incubated with or without various doses of CsA for 24 hours. (B) The confluent cells were incubated with or without $\mathrm{CsA}\left(10^{-6} \mathrm{M}\right)$ for the indicated time periods, and albumin was measured by enzyme-linked immunosorbent assay (ELISA). Olive oil was used as a vehicle. Data are expressed as mean $\pm \mathrm{SE}$. Values are means of four independent experiments performed in duplicate samples. ${ }^{*} p<$ 0.01 vs. control. (C) Western blot analysis for albumin in Huh7cell conditioned medium. The cells were incubated with or without various doses of CsA for 24 hours. Numbers on the left represent sizes in kilodaltons. Olive oil was used as a vehicle. Densitometric values are the mean of two experiments and are expressed as mean $\pm \mathrm{SE}$. 


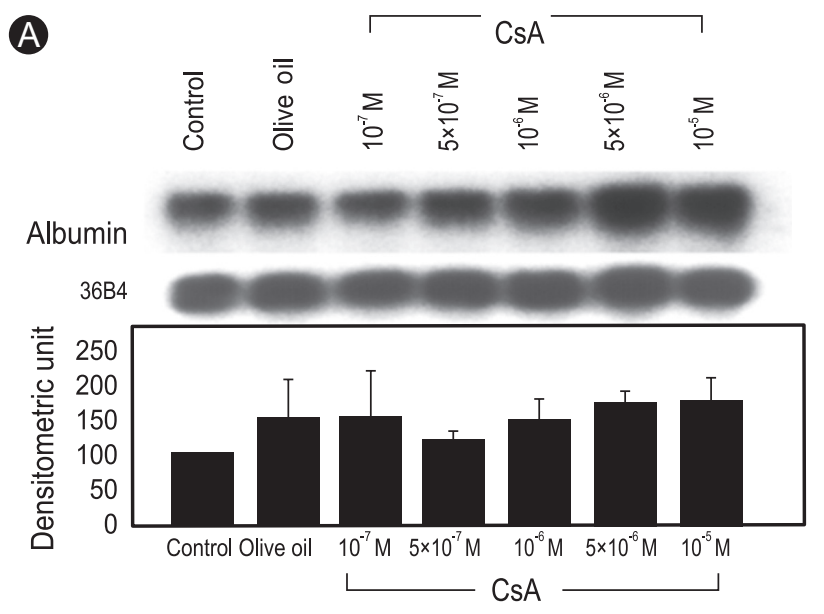

B

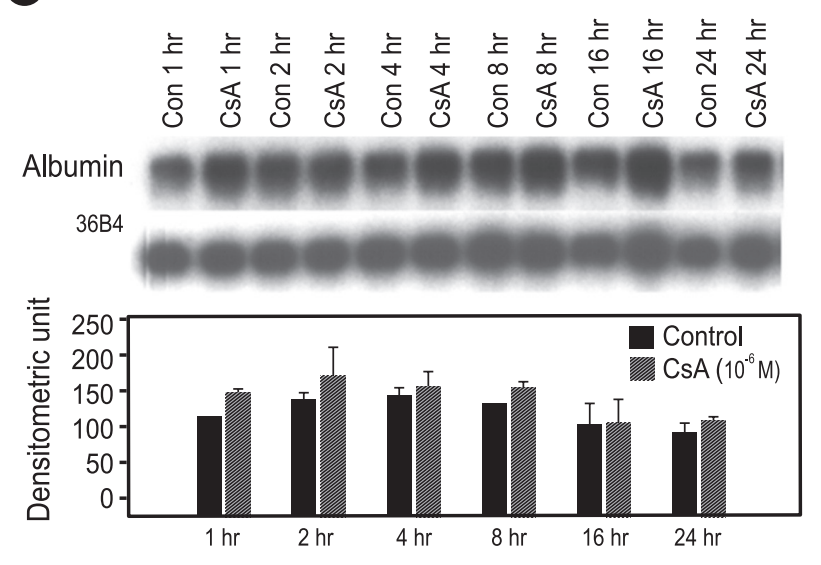

Figure 2. Northern blot analysis for albumin gene expression in Huh7 cells. (A) The confluent cells were incubated with or without various doses of cyclosporine A (CsA) for 24 hours, and total RNA was isolated. (B) Confluent cells were incubated with or without CsA $\left(10^{-6} \mathrm{M}\right)$. Total RNA was isolated after 1, 2, 4, 8, 16, and 24 hours. The figures in both (A) and (B) are representative of three experiments. Densitometric values are the mean of three experiments, and are expressed as mean $\pm \mathrm{SE}$.

experiment with trypan blue. More than $95 \%$ of cells treated with various concentrations of CsA were viable.

\section{Albumin gene expression}

The Northern blot analysis revealed that $\operatorname{CsA}\left(10^{-7}-10^{-5} \mathrm{M}\right)$ did not inhibit albumin mRNA expression in Huh7 cells after a 24 hours incubation (Fig. 2A). In the time course, albumin mRNA expression in the untreated cells peaked between 2 and 4 hours and then decreased gradually until 24 hours. However, no difference in albumin mRNA expression was observed at any time point from 1 to 24 hours between untreated and CsA-treated Huh7 cells, indicating that inhibition of albumin synthesis by CsA occurred at the translational level (Fig. 2B).

\section{DISCUSSION}

The principal finding of this study was that CsA inhibited translation of albumin synthesis in Huh7 cells. A special synthetic assembly line for the synthesis of proteins for export, including serum albumin, is present within hepatocytes. After DNA-directed specific RNA synthesis, the protein production process proceeds in the cytoplasm. The ribosome consists of two subunits, a smaller unit (40S) and a larger unit (6o-S). The smaller subunit is attached to mRNA, whereas the larger subunit is attached to the microtubular structure, the endoplasmic reticulum. As the albumin molecule is synthesized, it is inserted through the center of the larger subunit into the endoplasmic reticulum, and is then extruded into the hepatic plasma by traversing both the smooth endoplasmic reticulum and Golgi apparatus [7-9].

Huh7 cells have been used for biological assays and are known to secrete many endogenous proteins, including $\alpha$-fetoprotein, $\beta 2$-microgloblin, integrins and transferring [10-13]. Confluent Huh7 cells secreted a large amount of albumin, which accumulated continuously up to 48 hours. Our finding of a decreased amount of albumin in the conditioned medium released from CsA-treated Huh7 cells, without decreased albumin mRNA expression, indicates that CsA inhibits translation of albumin synthesis at the ribosome. The Western blot analysis of albumin from the conditioned medium also revealed that CsA inhibited albumin synthesis. However, further study is needed to compare albumin production between Huh7 cell lysates and conditioned medium, which would verify whether CsA blocks albumin secretion from the cytoplasm into conditioned medium.

CsA is hepatotoxic including inhibition of hepatic protein synthesis. CsA administered orally (100 mg/ $\mathrm{kg} /$ day) to rats for 21 days causes marked decreases in total serum protein and albumin, accompanied by rises in alkaline phosphatase and total bilirubin. A morphological examination of the liver revealed moderate centrilobular fatty changes and minor dilatation of endoplasmic reticulum [14]. In our experiments, more than 95\% of Huh7 cells treated with CsA were viable. Inhibition of hepatic 
albumin synthesis by CsA may occur independently of hepatotoxicity.

We also measured transferrin in the conditioned medium by direct ELISA, which is a protein typically produced in the liver. CsA significantly inhibited transferrin synthesis at $10^{-7} \mathrm{M}$ and higher doses in a dosedependent manner (data not shown). It is likely that CsA inhibits not only albumin synthesis but also synthesis of other proteins produced in the liver. A previous study showed that both albumin and transferrin levels were reduced in the supernatant treated with CsA [15]. Albumin and transferrin are negative acute-phase proteins that are excellent markers of mortality risk in patients with endstage renal disease $[16,17]$ and may contribute to mortality after kidney transplantation.

In many transplant centers, including ours, the CsA whole-blood trough level target during early renal transplantation period is approximately $400 \mathrm{ng} / \mathrm{mL}$, which accounts for $3 \times 10^{-7} \mathrm{M}$. In an animal study, CsA concentration in liver tissue was 9.5 times higher than that in blood [18]. Therefore, when the whole-blood trough level is $3 \times 10^{-7} \mathrm{M}$, the concentration in liver tissue may approach $2.85 \times 10^{-6} \mathrm{M}$. Furthermore, peak levels of CsA in blood are five times higher than trough levels. In this study, CsA significantly inhibited albumin synthesis in Huh7 cells at $10^{-6} \mathrm{M}$ or higher concentrations, which could be the liver tissue exposure level in transplant recipients. In all patients with post-transplant hypoalbuminemia, serum albumin levels increase gradually as CsA dose is serially reduced. This clinical finding seems to be associated with the observation that CsA-induced hepatotoxicity, including hypoalbuminemia, improves when CsA concentration in liver tissue is $<10^{-6} \mathrm{M}$.

Several studies have reported on the effect of tacrolimus (FK-506) and CsA on albumin secretion. In one study, FK506 did not influence albumin secretion, but CsA mildly inhibited albumin production in HepG2 cells. That study also showed that FK-506 but not CsA attenuated the inhibitory effect of interleukin-6 on albumin secretion [19]. Another study comparing a different effect of CsA and FK-506 on hepatic albumin secretion revealed that albumin and transferrin production in CsA-treated cells decreased significantly compared to that in solvent or FK506-treated cells [15]. Although CsA and FK-506 share the same mechanism of action in downregulating cytokines by inhibiting calcineurin, we assume that the inhibitory effect of CsA on albumin hepatic synthesis may not be through calcineurin inhibition.

The mechanisms and sites of albumin degradation have not been identified yet. The kidney has been shown not to play a significant role in albumin degradation in the normal state, but may play an active role in disease states. In a rat model of nephrotic syndrome, a bilateral nephrectomy decreases the absolute albumin catabolic rate by about $50 \%$. In the normal condition, small amounts of albumin, which traverse the glomerular filter, are catabolized by tubular cells. Electron microscopy has revealed albumin transport across the convoluted and proximal straight segments of the tubule [20-22]. However, it must be determined if albumin catabolism in the kidney increases following the administration of immunosuppressive agents or by transplantation surgery itself.

In conclusion, our results provide evidence that highdose CsA inhibits hepatic albumin synthesis at the level of translation, which is a mechanism for CsA-induced hepatotoxicity and might be a cause of hypoalbuminemia in renal transplant recipients during the early posttransplantation period. CsA-induced hypoalbuminemia needs to be included in the differential diagnosis of early acute renal dysfunction in renal transplant recipients.

\section{Conflict of interest}

No potential conflict of interest relevant to this article was reported.

\section{REFERENCES}

1. Dawidson IJ, Ar'Rajab A. Perioperative fluid and drug therapy during cadaver kidney transplantation. Clin Transpl 1992:267284.

2. Mouridsen HT, Faber M. Accumulation of serum-albumin at the operative wound site as a cause of postoperative hypoalbuminaemia. Lancet 1966;2:723-725.

3. Werner M, Odenthal D. Serum protein changes after gastrectomy as a model of acute phase reaction. J Lab Clin Med 1967;70:302-310.

4. Backman L, Appelkvist EL, Ringden O, Dallner G. Effects of cyclosporine A on hepatic protein synthesis. Transplant Proc 1988;20(3 Suppl 3):853-858.

5. Vine W, Billiar T, Simmons R, Bowers LD. Cyclosporineinduced hepatotoxicity: a microassay by hepatocytes in tissue 
culture. Transplant Proc 1988;20(3 Suppl 3):859-862.

6. Buss WC, Stepanek J, Bennett WM. Proposed mechanism of cyclosporine toxicity: inhibition of protein synthesis. Transplant Proc 1988;20(3 Suppl 3):863-867.

7. Rothschild MA, Oratz M, Schreiber SS. Albumin synthesis: 1. N Engl J Med 1972;286:748-757.

8. Rothschild MA, Oratz M, Schreiber SS. Albumin metabolism. Gastroenterology 1973;64:324-337.

9. Edwards K, Fleischer B, Dryburgh H, Fleischer S, Schreiber G. The distribution of albumin precursor protein and albumin in liver. Biochem Biophys Res Commun 1976;72:310-318.

10. Kawai HF, Kaneko S, Honda M, Shirota Y, Kobayashi K. Alphafetoprotein-producing hepatoma cell lines share common expression profiles of genes in various categories demonstrated by cDNA microarray analysis. Hepatology 2001;33:676-691.

11. Vraetz T, Ittel TH, van Mackelenbergh MG, Heinrich PC, Sieberth HG, Graeve L. Regulation of beta2-microglobulin expression in different human cell lines by proinflammatory cytokines. Nephrol Dial Transplant 1999;14:2137-2143.

12. Masumoto A, Arao S, Otsuki M. Role of beta1 integrins in adhesion and invasion of hepatocellular carcinoma cells. Hepatology 1999;29:68-74.

13. Trinder D, Zak O, Aisen P. Transferrin receptor-independent uptake of differic transferrin by human hepatoma cells with antisense inhibition of receptor expression. Hepatology 1996;23:15121520.

14. Blair JT, Thomson AW, Whiting PH, Davidson RJ, Simpson JG.
Toxicity of the immune suppressant cyclosporin A in the rat. J Pathol 1982;138:163-178.

15. Kruger B, Ulrich C, Kohler H, Riegel W. Different effects of cyclosporine or tacrolimus on hepatocyte acute phase proteins. Transplant Proc 1998;30:989-990.

16. Bergstrom J. Nutrition and mortality in hemodialysis. J Am Soc Nephrol 1995;6:1329-1341.

17. Lodish HF, Kong N. Cyclosporin A inhibits an initial step in folding of transferrin within the endoplasmic reticulum. J Biol Chem 1991;266:14835-14838.

18. Wagner O, Schreier E, Heitz F, Maurer G. Tissue distribution, disposition, and metabolism of cyclosporine in rats. Drug Metab Dispos 1987;15:377-383.

19. Li Y, Liu FY, Liu ZH, et al. Effect of tacrolimus and cyclosporine A on suppression of albumin secretion induced by inflammatory cytokines in cultured human hepatocytes. Inflamm Res 2006;55:216-220.

20. Mogielnicki RP, Waldmann TA, Strober W. Renal handling of low molecular weight proteins. I. L-Chain metabolism in experimental renal disease. J Clin Invest 1971;50:901-909.

21. Katz J, Bonorris G, Sellers AL. Albumin metabolism in aminonucleoside nephrotic rats. J Lab Clin Med 1963;62:910-934.

22. Bourdeau JE, Carone FA, Ganote CE. Serum albumin uptake in isolated perfused renal tubules: quantitative and electron microscope radioautographic studies in three anatomical segments of the rabbit nephron. J Cell Biol 1972;54:382-398. 